Case Report

\title{
Is It Possible to Maintain Consciousness and Spontaneous Ventilation with Chest Compression in the Early Phase of Cardiac Arrest?
}

\author{
Menekse Oksar and Selim Turhanoglu \\ Department of Anesthesiology and Reanimation, Mustafa Kemal University Faculty of Medicine, \\ 31100 Hatay, Turkey \\ Correspondence should be addressed to Menekse Oksar; menekseoksar@gmail.com
}

Received 29 October 2015; Revised 5 January 2016; Accepted 17 January 2016

Academic Editor: Pavel Michalek

Copyright (C) 2016 M. Oksar and S. Turhanoglu. This is an open access article distributed under the Creative Commons Attribution License, which permits unrestricted use, distribution, and reproduction in any medium, provided the original work is properly cited.

\begin{abstract}
Chest compression is important in cardiopulmonary resuscitation. However, life support algorithms do not specify when chest compression should be initiated in patients with persistent spontaneous normal breathing in the early phase after cardiac arrest. Here we describe the case of a 69 -year-old man who underwent femoral bypass surgery and was extubated at the end of the procedure. After extubation, the patient's breathing pattern and respiratory rate were normal. The patient subsequently developed ventricular fibrillation, evident on two monitors. Because defibrillation was ineffective, chest compression was initiated even though the patient had spontaneous normal breathing and defensive motor reflexes, which were continued throughout resuscitation. He regained consciousness and underwent tracheal extubation without neurological sequelae on postoperative day 1 . This case highlights the necessity of chest compression in the early phase of cardiac arrest.
\end{abstract}

\section{Introduction}

The 2010 American Heart Association recommendations and European Resuscitation Council guidelines for cardiopulmonary resuscitation (CPR) focus on the requirement of immediately initiating chest compression and ventilation to maintain cerebral blood flow and adequate gas exchange, respectively [1]. Maintaining cerebral perfusion prevents neurological damage. Some studies have shown that conscious, spontaneous breathing may continue for a short time after cerebral perfusion stops; for example, repeated rhythmic coughs every 1-3s maintained consciousness for up to $39 \mathrm{~s}$ in three patients who developed ventricular fibrillation during coronary arteriography [2]. Cardiac arrest survivors recall memories of awareness, fear, and persecution after CPR [3]. Early diagnosis of cardiac arrest may prolong spontaneous breathing and consciousness by maintaining cerebral perfusion through effective chest compression. We present a 69 -year-old man with uninterrupted spontaneous normal breathing during CPR.

\section{Case Report}

A 69-year-old man (American Society of Anesthesiologists class 2; weight $70 \mathrm{~kg}$; height $1.72 \mathrm{~m}$ ) with peripheral arterial disease and diabetes mellitus underwent femoral bypass surgery. Anesthesia was induced using $2 \mathrm{mg}$ midazolam, $100 \mu \mathrm{g}$ fentanyl, and $2 \mathrm{mg} / \mathrm{kg}$ propofol. Endotracheal intubation was achieved with $40 \mathrm{mg}$ rocuronium, anesthesia was maintained by $2 \%$ sevoflurane with $\mathrm{N}_{2} \mathrm{O}$ and $50 \% \mathrm{O}_{2}$, and diuretic and insulin infusions were administered as required. The patient showed normal blood gas levels $(\mathrm{pH}$, 7.36; $\mathrm{PaCO}_{2}$, $43 \mathrm{mmHg} ; \mathrm{PaO}_{2}, 92 \mathrm{mmHg}$; lactate, $3.5 \mathrm{mmol} / \mathrm{L}$; and base excess, $1.2 \mathrm{mmol} / \mathrm{L}$ ). His blood glucose level was $220 \mathrm{mg} / \mathrm{dL}, \mathrm{O}_{2}$ saturation level was $99 \%$ on $50 \% \mathrm{O}_{2}$, heart rate (HR) was 88 beats/min, and mean arterial pressure (MAP) was $70 \mathrm{mmHg}$. Neuromuscular blockade was reversed using $200 \mathrm{mg}$ sugammadex, and the patient was extubated. Thereafter, his breathing pattern was regular, with a respiratory rate of 17 breaths/min and a tidal volume of $600 \mathrm{~mL}$. Oxyhemoglobin saturation determined using pulse oximetry 
was 99\%, invasive arterial blood pressure was 140/90 $\mathrm{mmHg}$ (MAP, $106 \mathrm{mmHg}$ ), and HR was 100 beats/min. Further, a transport monitor was connected.

The patient subsequently developed ventricular fibrillation (VF), evident on 2 monitors. A biphasic 150-J shock was administered immediately, and ventilation was initiated with a facemask supplying $\mathrm{O}_{2}$ at $6 \mathrm{~L} / \mathrm{min}$ before his trachea was reintubated without a neuromuscular blocking agent. Ventilatory support was manually administered because he was breathing spontaneously. After the first shock, external cardiac massage was applied for $2 \mathrm{~min}$. However, the patient remained in VF; therefore, a second shock was administered, followed by further chest compression. The patient became asystolic and received $1 \mathrm{mg}$ intravenous epinephrine. Although spontaneous breathing persisted, CPR was continued. Shocks and chest compression continued for $1 \mathrm{~h}$, with epinephrine administered every 3-5 min with short breaks to assess cardiac rhythm. The chest compression evoked defensive motor reflexes, such as flexion of the neck, trunk, and arms, and arterial traces were determined to originate from external cardiac massage during resuscitation.

During resuscitation, arterial blood gas recordings showed acidosis with an abnormally low $\mathrm{pH}$, high lactate, and low base excess. $\mathrm{PaCO}_{2}$ was normal during $\mathrm{VF}$ and resuscitation, but it increased by the end of resuscitation. Although assisted breathing was provided throughout resuscitation, the rate of spontaneous breathing was 16-17 breaths/min with a tidal volume of $600 \mathrm{~mL} / \mathrm{min}$. During resuscitation, endtidal $\mathrm{CO}_{2}$ was $19-22 \mathrm{mmHg}$. The potassium level was normal intraoperatively $(3.6 \mathrm{mmol} / \mathrm{L})$, reduced during resuscitation $(2.0 \mathrm{mmol} / \mathrm{L})$, and increased with potassium replacement therapy by the end of resuscitation $(3.2 \mathrm{mmol} / \mathrm{L})$. The patient remained asystolic until circulation resumed spontaneously. After resuscitation, the $\mathrm{HR}$ was recorded at 51 beats/min with ST depression observed on electrocardiography (ECG) (Table 1). Measurements recorded at baseline, preoperatively, during CPR, and after CPR are shown in Table 1. Spontaneous breathing continued without interruption throughout the entire CPR period. Following tracheal intubation, ventilation was manually assisted with the balloon of a breathing circuit throughout the entire CPR period and an Ambu bag during patient transfer following resuscitation. The actual measured duration of asystole was $50 \mathrm{~min}$. VF lasted for approximately 10 minutes. During cardiac arrest, defibrillation attempts were made and chest compression was initiated in order to maintain adequate blood pressure. CPR was continued until potential underlying correctable causes of VF (such as the hypokalemia and low arterial $\mathrm{pH}$ levels in the present case) were determined and corrective interventions could be performed. Approximately 1 hour after correction of the metabolic causes of VF, during which spontaneous breathing and continued motor responses to chest compression without QRS complexes on electrocardiography were observed, the patient was reviewed by a cardiologist and was subsequently transferred to coronary angiography for further investigations. ECG and ventilatory data at the end of CPR were given as supplementary material (Figure S1 in Supplementary Material available online at http://dx.doi.org/ $10.1155 / 2016 / 3158015)$.
During angiography, the patient again developed asystole requiring further chest compression but responded to CPR and was transferred to the cardiovascular surgery intensive care unit. Coronary angiography was reported as normal. The patient regained consciousness on postoperative day 1, was extubated, and showed no evidence of neurological sequelae. Written consent for the publication of this report was obtained from the patient postoperatively.

\section{Discussion}

A significantly increased incidence of ventricular tachycardia (VT) and VF has been reported after reperfusion therapy for patients with myocardial infarction and systemic acidosis [4]. There is evidence that systemic metabolic acidosis is a strong predictor of VT/VF after reperfusion of ST-elevation myocardial infarction associated with inflammation [5]. However, the causal relationship between systemic acidosis secondary to myocardial ischemia and VT/VF is complex, and the trigger is not always obvious. In this case, the lactic acidosis after surgical clamping coupled with the final low $\mathrm{HCO}_{3}{ }^{-}$may have created a high-anion-gap metabolic acidosis that caused VF. Another possibility is that using insulin or diuretics caused hypokalemia, which induced VF.

Although VF is the most frequent cause of cardiac arrest and death, it is reversible if treated early. Failure to commence CPR between cardiac arrest and the cessation of spontaneous breathing may cause irreversible brain injury. Therefore, current guidelines recommend immediate chest compression for unresponsive patients who are breathing abnormally [6]. For spontaneously breathing patients who are unresponsive or unconscious, guidelines recommended they should be placed in the recovery position because spontaneous breathing is considered a reliable sign of effective cardiac activity [1]. However, a few reports have demonstrated that normal spontaneous breathing, and even consciousness, continues for a short time after a cardiac arrest.

In one study of 8 patients, breathing pattern, frequency, and tidal volume were found to be unchanged in the first $12-$ $15 \mathrm{~s}$ of VF [7]. These findings were confirmed in adult sheep, where breathing patterns were unchanged for $15 \mathrm{~s}$ and minute ventilation increased for $55 \pm 44 \mathrm{~s}$ before stopping abruptly. Agonal breathing efforts have been reported to begin $37 \pm 38 \mathrm{~s}$ into the apneic period, whereas there is evidence that normal breathing ceases after $12-60 \mathrm{~s}$ and that agonal breathing can persist for up to $6 \mathrm{~min}$ [8]. Agonal breathing was reported in $40 \%$ of 445 out-of-hospital cardiac arrests, where it was more frequent in patients with VF and was associated with increased survival [9]. Our patient continued to breathe spontaneously throughout CPR, perhaps because of the early and uninterrupted breathing support, and we did not detect agonal breathing.

As mentioned previously, rhythmic coughs have been shown to prolong consciousness in VF [2], whereas survivors of cardiac arrest have reported a broad range of cognitive experiences. Furthermore, 2\% (2 of 101 patients) have reported retaining full awareness [3]. Although it is unclear whether the experiences during cardiac arrest refer to actual events or hallucinations, the finding that conscious 


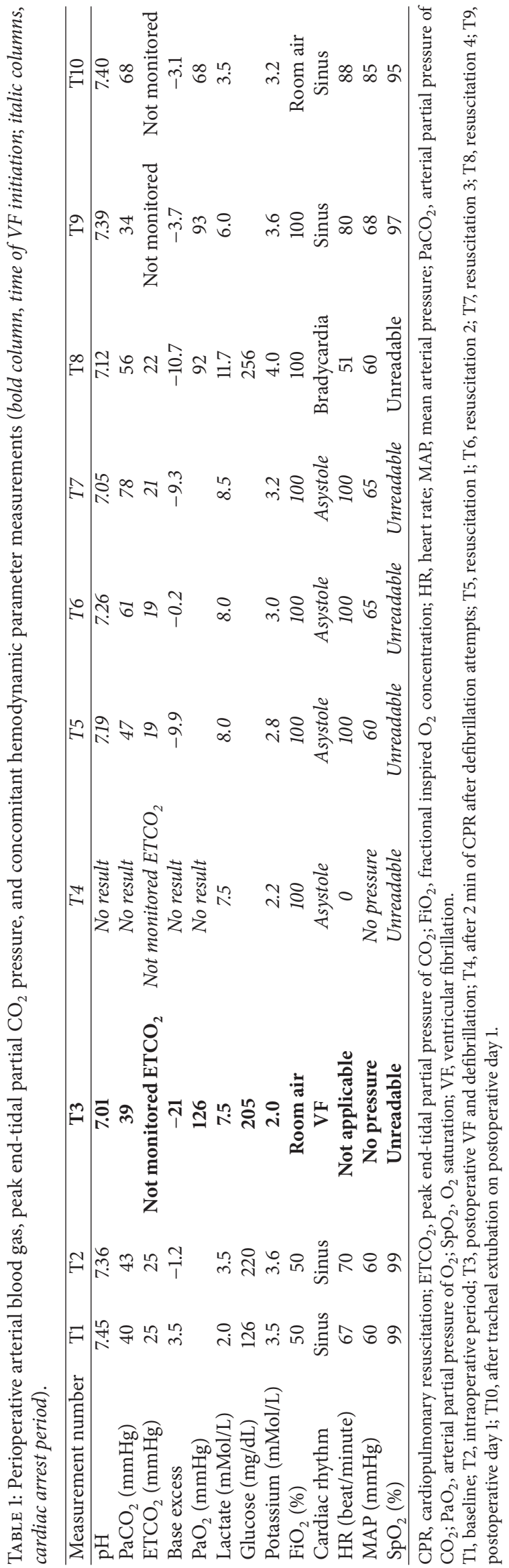


awareness can remain during cardiac arrest is intriguing and supports other recent studies indicating that consciousness may be present despite clinically undetectable consciousness. Another report has suggested that functional neuroimaging techniques can assist with the prognosis and diagnosis of patients with disorders of consciousness [10]. Notably, our patient displayed defensive motor reflexes in response to painful stimuli (chest compression) but denied any recollection.

In conclusion, because respiratory neurons can maintain respiration immediately after cardiac arrest, it can be misleading to assume that any normal breathing movements preclude a diagnosis of cardiac arrest. Therefore, the first 10-15s of a witnessed cardiac arrest are crucial to save patients' lives and prevent neurological sequelae. Although intervention during this time is critical, it will be difficult to implement appropriate interventions with unmonitored patients.

\section{Conflict of Interests}

The authors declare that there is no conflict of interests regarding the publication of this paper.

\section{References}

[1] J. P. Nolan, J. Soar, D. A. Zideman et al., "European resuscitation council guidelines for resuscitation 2010 section 1. Executive summary," Resuscitation, vol. 81, no. 10, pp. 1219-1276, 2010.

[2] J. M. Criley, A. H. Blaufuss, and G. L. Kissel, "Self administered cardiopulmonary resuscitation by cough induced cardiac compression," Transactions of the American Clinical and Climatological Association, vol. 87, pp. 138-146, 1976.

[3] S. Parnia, K. Spearpoint, G. de Vos et al., "AWARE-AWAreness during REsuscitation-a prospective study," Resuscitation, vol. 85, no. 12, pp. 1799-1805, 2014.

[4] T. Nagai, T. Anzai, H. Kaneko et al., "Impact of systemic acidosis on the development of malignant ventricular arrhythmias after reperfusion therapy for ST-elevation myocardial infarction," Circulation Journal, vol. 74, no. 9, pp. 1808-1814, 2010.

[5] S. Niwano and T. Tojo, "Systemic acidosis in acute myocardial ischemia-cause or result of life-threatening ventricular arrhythmia?" Circulation Journal, vol. 74, no. 9, pp. 1794-1795, 2010.

[6] R. A. Berg, R. Hemphill, B. S. Abella et al., "Part 5: adult basic life support: 2010 American Heart Association Guidelines for Cardiopulmonary Resuscitation and Emergency Cardiovascular Care," Circulation, vol. 122, no. 3, pp. S685-S705, 2010.

[7] P. Haouzi, N. Ahmadpour, H. J. Bell et al., "Breathing patterns during cardiac arrest," Journal of Applied Physiology, vol. 109, no. 2, pp. 405-411, 2010

[8] M. W. Kroll, D. R. Lakkireddy, J. R. Stone, and R. M. Luceri, "TASER electronic control devices and cardiac arrests: coincidental or causal?" Circulation, vol. 129, no. 1, pp. 93-100, 2014.

[9] J. J. Clark, M. P. Larsen, L. L. Culley, J. R. Graves, and M. S. Eisenberg, "Incidence of agonal respirations in sudden cardiac arrest," Annals of Emergency Medicine, vol. 21, no. 12, pp. 14641467, 1992.

[10] D. Cruse and A. M. Owen, "Consciousness revealed: new insights into the vegetative and minimally conscious states," Current Opinion in Neurology, vol. 23, no. 6, pp. 656-660, 2010. 


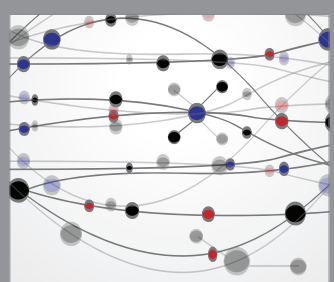

The Scientific World Journal
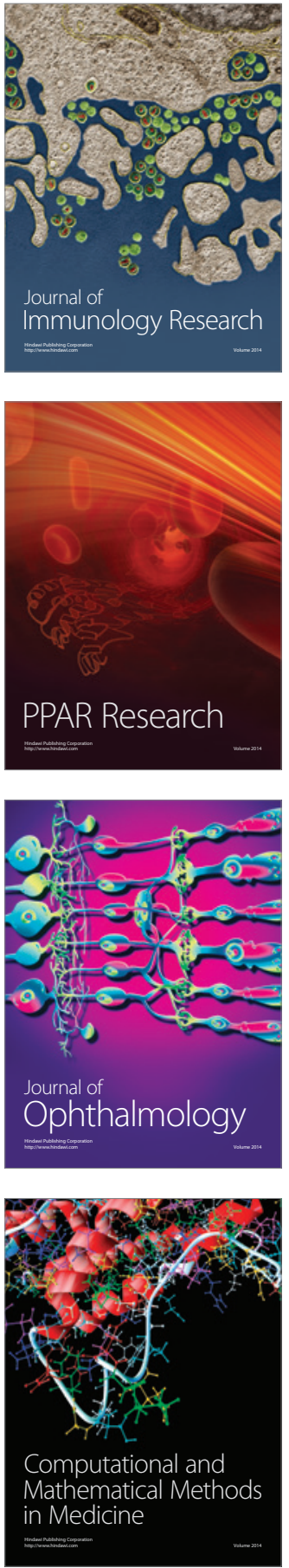

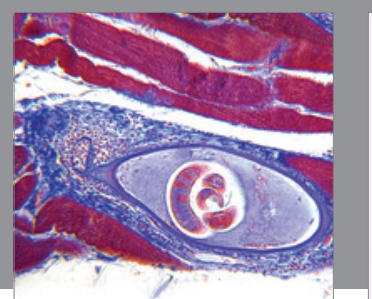

Gastroenterology Research and Practice

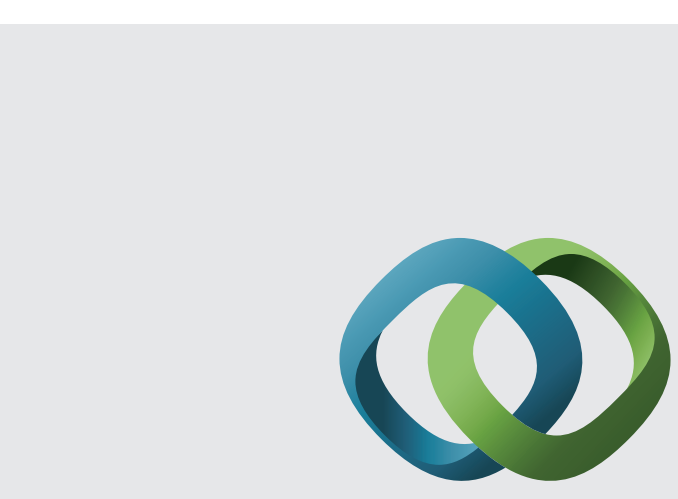

\section{Hindawi}

Submit your manuscripts at

http://www.hindawi.com
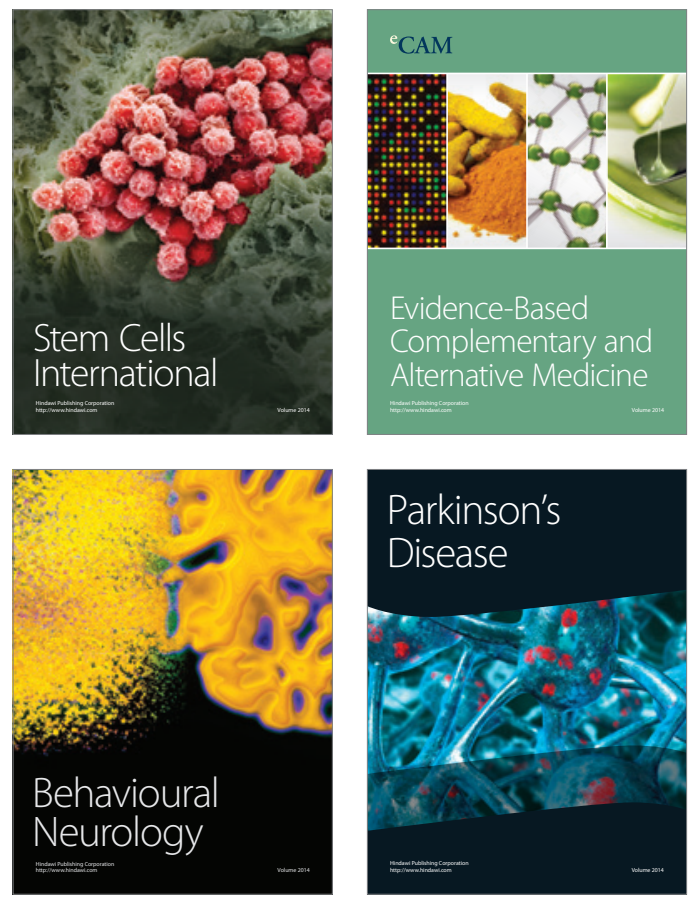
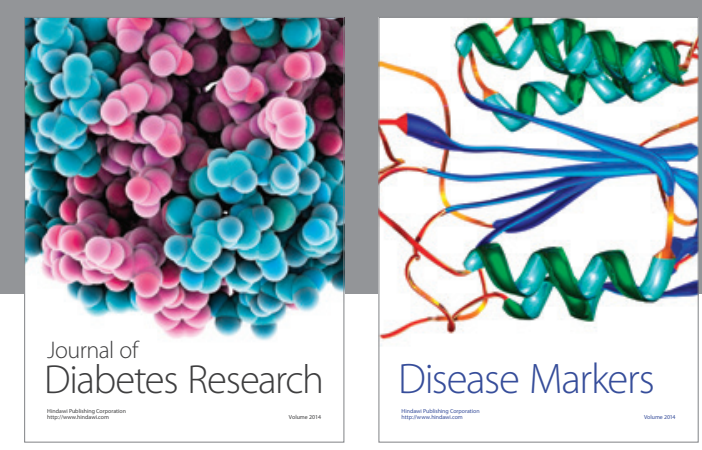

Disease Markers
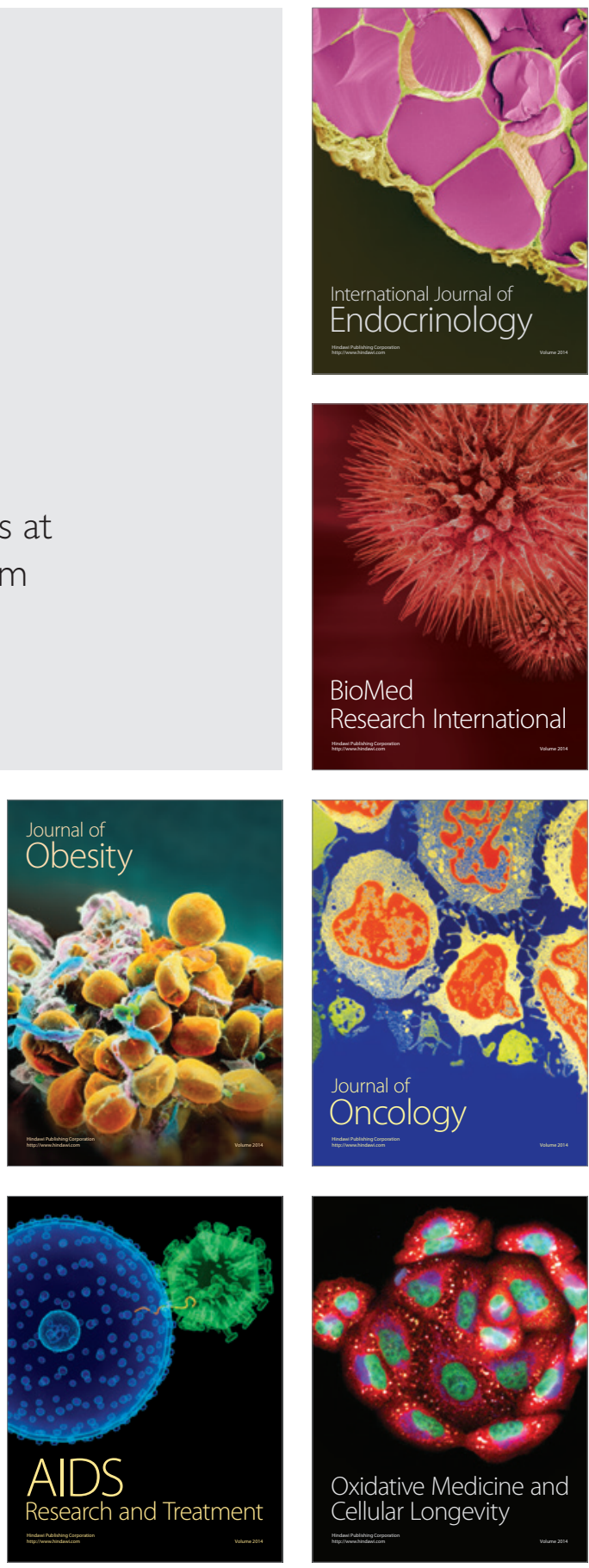